\title{
The effect of fruit on the extracellular enzyme profiles of fungi
}

\author{
Ewelina Farian ${ }^{1, A-D, F \oplus}$, Grażyna Cholewa ${ }^{1, A-C, E \oplus}$, Alicja Cholewa ${ }^{1, A-C, F \oplus}$, Magdalena Matczuk $k^{1, A-B, E \oplus}$, \\ Angelina Wójcik-Fatla ${ }^{1, A, C, E-F}$ (1) \\ ${ }^{1}$ Department of Biological Health Hazards and Parasitology, Institute of Rural Health, Lublin, Poland \\ A - Research concept and design, B - Collection and/or assembly of data, C - Data analysis and interpretation, \\ $D$ - Writing the article, $E$ - Critical revision of the article, F - Final approval of article
}

\begin{abstract}
Farian E, Cholewa G, Cholewa A, Matczuk M, Wójcik-Fatla A. The effect of fruit on the extracellular enzyme profiles of fungi. Ann Agric
\end{abstract} Environ Med. 2020; 27(4): 562-567. doi: 10.26444/aaem/127557

\begin{abstract}
Introduction. In recent years, the number of diseases caused by fungal pathogens has increased significantly. Many species of fungi are pathogenic for plants, causing a threat to food production and to humans, and are among the causes of chronic diseases.

Objective. The aim of the study is to determine the enzyme profiles of fungi, depending on the different types of fruit with which they have contact, and to determine the differences in these profiles in relation to the substrate on which they are grown.

Materials and method. Six strains of fungi identified as Cladosporium sphaerospermum, Fusarium poae, Alternaria alternata, Penicillium expansum, Penicillium verucosum and Acremonium strictum, isolated from fruits, were selected and analyzed for enzymatic profiles. The enzymatic activity was assessed using the API ZYM test (bioMerieux, France).

Results. In the majority of the 6 fungal strains isolated from fruits, enzymes belonging to glycol-hydrolases were the most active. The exception was Acremonium strictum, where phosphatases dominated. Among most fungal isolates, the enzymes $\beta$-glucosidase and $\mathrm{N}$-acetyl- $\beta$-glucosaminidase showed the highest activity. The highest $\beta$-glucosidase activities were found in Cladosporium sphaerospermum and Penicillium expansum. On the other hand, lipase, a-fucosidase and a-chymotrypsin showed the least activity. The least activity of these enzymes or their complete absence was observed in Fusarium poae, Alternaria alternata, Penicillium expansum and Acremonium strictum.

Conclusions. The activity of hydrolytic enzymes in the isolated fungi depended on the addition of fruit and the type of medium. Individual fruits can increase or decrease the activity of the enzymes. Fungi present in fruit have pathogenic properties and can be possible risk factors for fungal infections.
\end{abstract}

\section{Key words}

fungi, enzymatic activity, hydrolytic enzymes, fresh fruit, API ZYM

\section{INTRODUCTION}

Fungi are commonly found in the environment and their main function is recycling nutrients contained in organic matter [1]. Many species of fungi are pathogenic for both plants and humans. In recent years, the number of diseases caused by fungal pathogens has increased significantly [2]. Many species of fungi are pathogenic for plants, causing a threat to food production and to humans, and are among the causes of chronic diseases [3,4]. Considering the diversity of fungal infections, they can be divided into two groups: saprophytic opportunistic fungi that cause endogenous infections by penetration through damaged epidermis or weakened host's immune system, and primary pathogens that can cause disease in all humans, regardless of their health condition $[1,5]$.

Due to the increasing amount of fruit consumed, phytopathogenic fungi are a growing threat $[1,6]$. Phytopathogens are one of the fruit spoilage factors [7]. Ripe fruits contain many compounds (including saccharides, proteins, phenols) that can be the main source of carbon and

Address for correspondence: Ewelina Farian, Department of Biological Health Hazards and Parasitology, Institute of Rural Health, Jaczewskiego 2, 20-090 Lublin, Poland

E-mail: farian.ewelina@imw.lublin.pl

Received: 06.07.2020; accepted: 16.09.2020; first published: 29.09.2020 nitrogen for many microorganisms. Fresh fruits, referred to as food products, are living tissues that have evolved many mechanisms to prevent invasion by fungi. These mechanisms can be the basis for the creation of specific interactions between a fruit and a species of mould, leading to the destruction of tissues [8].

The penetration of pathogens into the organism allows, among others, the ability to secrete extracellular enzymes. Fungi are one of the most commonly described pathogens in terms of the ability to produce hydrolytic enzymes, which are very important virulence factors, including proteases, lipases and phosphatases [9]. Many of these enzymes may cause serious adverse reactions [10].

In plants, hydrolytic enzymes damage the components of the cell wall, which allows phytopathogenic microorganisms to penetrate into the inner layers of the plant $[8,11]$. These fungi attack not only plants, but may also pose a threat to people who come into contact with them [12]. In the case of humans, fungal pathogenicity is the enzymatic breakdown of the components of human skin, at the same time leading to the degradation of the natural barrier that protects against the invasion of microorganisms [13]. Hydrolytic enzymes also have the ability to attack cells of the immune system which constitute the defence mechanisms of the host [14].

It is very important to understand the interaction between fruit and mould and their possible impact on human health. 
However, there are few papers on the effect of fruits on the production of fungal hydrolytic enzymes as virulence factors.

\section{OBJECTIVE}

The aim of the study is to determine the enzyme profiles of fungi, depending on the different types of fruit with which they have contact, and to determine the differences in these profiles in relation to the substrate on which they are grown.

\section{MATERIALS AND METHOD}

Six strains of fungi identified as Cladosporium sphaerospermum, Fusarium poae, Alternaria alternata, Penicillium expansum, Penicillium verrucosum and Acremonium strictum, were isolated from fruits, and selected and analyzed for enzymatic profiles (Tab. 1). The abovespecies constitute a breeding collection of the Department of Biological Health Hazards and Parasitology at the Institute of Rural Health in Lublin. Isolated fungal species were grown on solid media Malt Agar (Becton, Dickinson and Co.) and tested by the API ZYM test (bioMerieux, France). This test comprises 19 specific substrates to assess the hydrolytic activity of the following enzymes: alkaline phosphatase, esterase, esterase lipase, lipase, leucine arylamidase, valine arylamidase, cystine arylamidase, trypsin, $\alpha$-chymotrypsin, acid phosphatase, naphthol-AS-BI-phosphohydrolase, $\alpha$-galactosidase, $\beta$-galactosidase, $\beta$-glucuronidase $\alpha$-glucosidase, $\beta$-glucosidase, $\mathrm{N}$-acetyl- $\beta$-glucosidaminidase, $\alpha$-mannosidase and $\alpha$-fucosidase. Fragments $1 \mathrm{~cm}^{2}$ in volume were taken from the obtained colonies and placed in two liquid mediums of Czapek Dox Broth (Becton, Dickinson and Co.) with 5\% fruit addition (strawberry, raspberry or apple) and Sabouraud Broth (Becton, Dickinson and Co.) with $5 \%$ fruit addition (strawberry, raspberry or apple). The media with fruit addition were sterilized by autoclaving for 15 minutes at $121^{\circ} \mathrm{C}$. Media inoculated with fungi but without the addition of fruit were used as controls. The isolates were incubated for 24 days at $30^{\circ} \mathrm{C}$. Supernatants obtained from the culture by centrifugation or sedimentation were used for the tests. The test procedure was performed according to the manufacturer's instructions, by adding $65 \mu \mathrm{l}$ of the supernatant in the appropriate wells of the test strip. The strips were placed in a moist chamber and incubated at $37^{\circ} \mathrm{C}$ for four hours.

After incubation, the enzyme activity was inhibited by adding one drop of reagents ZYM A and ZYM B. The results of the enzymatic activity were assessed visually according to the table attached to the tests by the manufacturer, on a point scale from $0-5$, depending on the intensity of the colour reaction. The enzyme activity was determined in nanomols of the hydrolyzed substrate according to Bang and Chung [15], with 0 being the total absence of the enzyme, whereas the 1-5 scale was in the range $1-5 \mathrm{nmol}, 2-10 \mathrm{nmol}, 3$ $20 \mathrm{nmol}$, and $4-30 \mathrm{nmol}$, respectively, and 5 - 40 nmoles or more. Differences in enzyme activity were compared in terms of utilization of the organic substrates and type of medium.
Table 1. Site of isolation of individual species of fung

\begin{tabular}{lc}
\hline Species & Type of fruits \\
\hline Cladosporium sphaerospermum & strawberry \\
\hline Fusarium poae & strawberry \\
\hline Alternaria alternata & raspberry \\
\hline Acremonium strictum & raspberry \\
\hline Penicillium expansum & apple \\
\hline Penicillium verrucosum & apple \\
\hline
\end{tabular}

Statistical analysis. The obtained results of the enzymatic activity of fungi without the addition of fruit and with the addition of fruit from which the fungi were isolated were statistically analyzed using the non-parametric Wilcoxon and Mann-Whitney tests. The data were analyzed using computer programme Statistica 13.1. A p-value less than 0.05 was regarded as significant.

\section{RESULTS}

The API ZYM test performed on controls (liquid mediums with and without added fruit) did not show hydrolytic enzymes activity. In the majority of the six fungal strains isolated from fruits, enzymes belonging to glycol-hydrolases achieved the greatest activity (Fig. 1). The exception was Acremonium strictum where phosphatases dominated. Among most fungal isolates, the enzymes $\beta$-glucosidase and $\mathrm{N}$-acetyl- $\beta$-glucosaminidase showed the highest activity (Tab. 2). The highest $\beta$-glucosidase activities (40 nmoles or more of the hydrolyzed substrate) were found in Cladosporium sphaerospermum and Penicillium expansum. On the other hand, lipase, $\alpha$-fucosidase and $\alpha$-chymotrypsin showed the least activity. The least activity (below 5 nmoles of hydrolyzed substrate) of these enzymes or their complete absence was observed in Fusarium poae, Alternaria alternata, Penicillium expansum and Acremonium strictum.

The results showed that the species C. sphaerospermum (eight enzymes), F.poae (seven enzymes), A. alternata (nine enzymes), $F$. expansum (eight enzymes) and $P$. verrucosum (six enzymes) produced the largest number of enzymes on the Sabourauda medium with the addition of strawberries, with activity in the range of 20-40 nmoles (scale 3-5) of the hydrolyzed substrate. In the case of C. sphaerospermum and F. poae, the addition of raspberries caused a significant decrease in the number of enzymes with activity in the range of 20-40 nmoles of the hydrolyzed substrate. However, in the case of A. alternata, $P$. expansum, and A. strictum, the addition of apples caused an increase in the number of enzymes with activity in the range of 20-40 nmoles of the hydrolyzed substrate.

The highest enzymatic activity was found in strains belonging to the genus Penicillium, including P. expansum and P. verrucosum (Tab. 3). The highest enzymatic activity of these fungi was recorded on medium with the addition of apple, the site of isolation of both strains. In the case of both species, for the Czapek-Dox medium with 5\% apple, the maximum activity ( 40 nmoles or more of the hydrolyzed substrate) was achieved by four enzymes: acid phosphatase, $\beta$-galactosidase, $\beta$-glucosidase, and $\mathrm{N}$-acetylglucosaminidase. The Sabouraud medium with $5 \%$ addition of these fruits, showed differences in the maximum activity of individual enzymes for 
a)
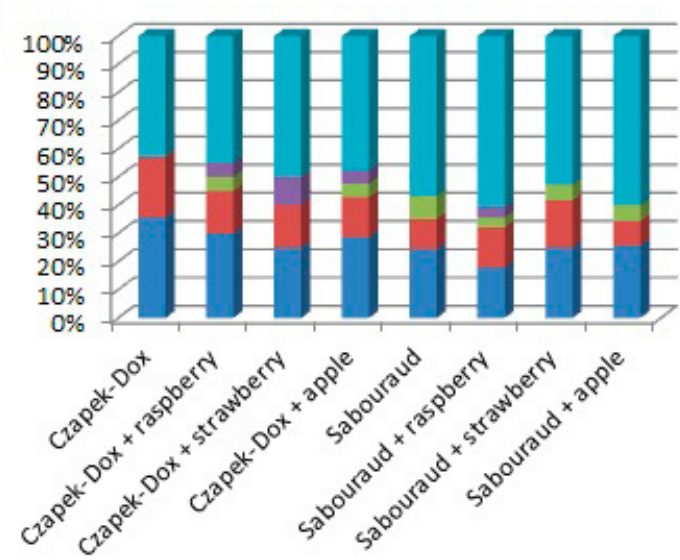

c)
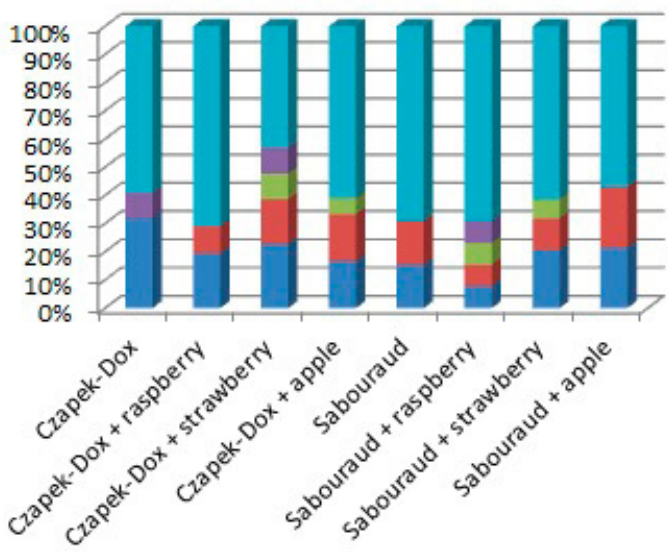

e)
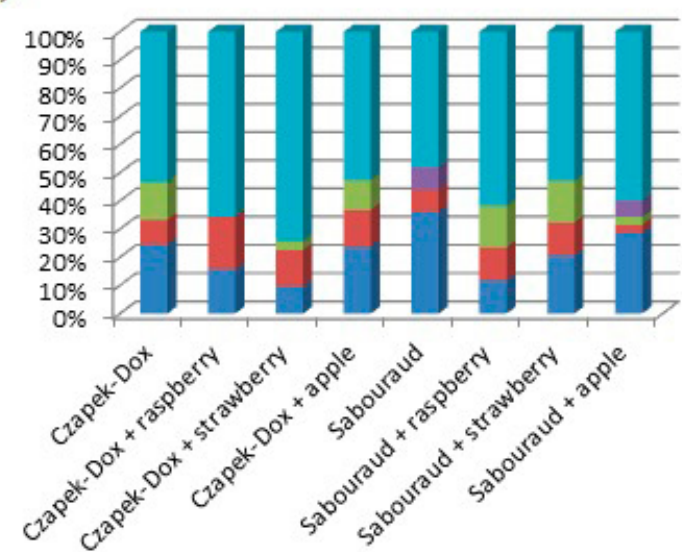

b)
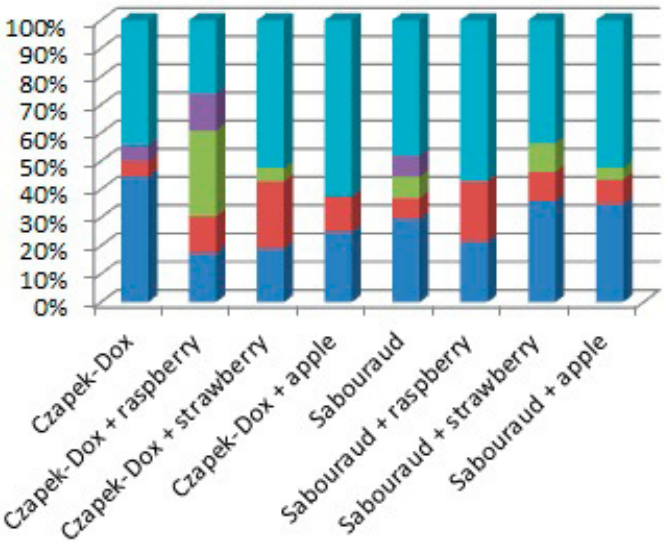

d)
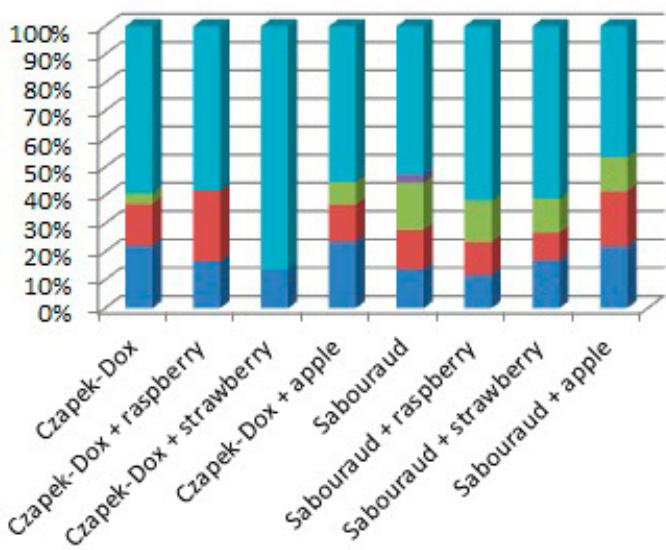

f)
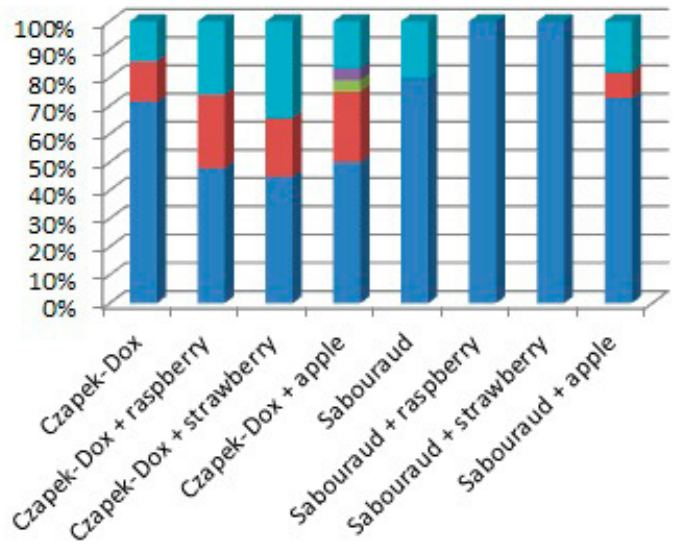

Mhosphtase Esterase Amino-peptidase Mroteases Glycol-hydrolases

Figure 1. Share of individual groups of hydrolases in total enzymatic activity of fungi isolated from fruits: a) Cladosporium sphaerospermum, b) Fusarium poae, c) Alternaria alternata, d) Penicillium expansum, e) Penicillium verrucosum, f) Acremonium strictum

P. expansum and P. verrucosum strains. P. expansum achieved maximum activity for five enzymes: alkaline phosphatase, leucine arylamidase, $\alpha$-galactosidase, $\beta$-galactosidase, and $\beta$-glucosidase. On the other hand, $P$. verrucosum, achieved maximum activity for four enzymes: acid phosphatase, naphthol-AS-BI-phosphohydrolase, $\beta$-glucuronidase and $\beta$-glucosidase.
On the other side, the lowest activity and the lowest amount of active enzymes was found in A. strictum. A. strictum culture on Sabouraud medium with 5\% addition of strawberries showed only the activity of two enzymes (acid phosphatase, naphthol-AS-BI-phosphohydrolase) at five nmol of hydrolysed substrate. In the case of $A$. alternata, $\boldsymbol{\alpha}$-galactosidase was active on Sabouraud medium only in the presence of strawberries. 
Table 2. Activity of hydrolytic enzymes from fungi isolated on a substrate with and without the addition of fruit

\begin{tabular}{|c|c|c|c|c|c|c|c|c|c|c|c|c|c|c|c|c|c|c|c|}
\hline \multirow{2}{*}{ Medium } & \multicolumn{19}{|c|}{ Enzyme activity* } \\
\hline & 1 & 2 & 3 & 4 & 5 & 6 & 7 & 8 & 9 & 10 & 11 & 12 & 13 & 14 & 15 & 16 & 17 & 18 & 19 \\
\hline \multicolumn{20}{|c|}{ Cladosporium sphaerospermum } \\
\hline Czapek-Dox & 2 & 3 & 3 & 0 & 0 & 0 & 0 & 0 & 0 & 4 & 4 & 5 & 0 & 1 & 0 & 5 & 1 & 0 & 0 \\
\hline Czapek-Dox + raspberry & 1 & 2 & 1 & 0 & 0 & 1 & 0 & 1 & 0 & 2 & 3 & 3 & 0 & 0 & 0 & 5 & 1 & 0 & 0 \\
\hline Czapek-Dox + strawberry & 1 & 2 & 1 & 0 & 0 & 0 & 0 & 1 & 1 & 1 & 3 & 4 & 0 & 0 & 0 & 5 & 1 & 0 & 0 \\
\hline Czapek-Dox + apple & 1 & 2 & 1 & 0 & 1 & 0 & 0 & 1 & 0 & 2 & 3 & 4 & 0 & 0 & 0 & 5 & 1 & 0 & 0 \\
\hline Sabouraud & 3 & 3 & 1 & 0 & 1 & 1 & 1 & 0 & 0 & 3 & 3 & 4 & 2 & 0 & 1 & 5 & 5 & 3 & 1 \\
\hline Sabouraud + raspberry & 1 & 2 & 2 & 0 & 1 & 0 & 0 & 1 & 0 & 2 & 2 & 5 & 1 & 0 & 1 & 5 & 3 & 1 & 1 \\
\hline Sabouraud + strawberry & 3 & 3 & 3 & 0 & 1 & 0 & 1 & 0 & 0 & 3 & 3 & 5 & 2 & 0 & 2 & 5 & 3 & 2 & 0 \\
\hline Sabouraud + apple & 3 & 2 & 1 & 0 & 1 & 1 & 0 & 0 & 0 & 3 & 3 & 5 & 2 & 0 & 0 & 5 & 5 & 2 & 2 \\
\hline
\end{tabular}

\section{Fusarium poae}

Czapek-Dox

Czapek-Dox + raspberry

Czapek-Dox + strawberry

Czapek-Dox + apple

Sabouraud

Sabouraud + raspberry

Sabouraud + strawberry

Sabouraud + apple

\section{Alternaria alternata}

Czapek-Dox

Czapek-Dox + raspberry

Czapek-Dox + strawberry

Czapek-Dox + apple

Sabouraud

Sabouraud + raspberry

Sabouraud + strawberry

Sabouraud + apple

Penicillium expansum

Czapek-Dox

Czapek-Dox + raspberry

Czapek-Dox + strawberry

Czapek-Dox + apple

Sabouraud

Sabouraud + raspberry

Sabouraud + strawberry

Sabouraud + apple

\section{Penicillium verrucosum}

Czapek-Dox

Czapek-Dox + raspberry

Czapek-Dox + strawberry

$\begin{array}{llllllll}0 & 1 & 0 & 0 & 0 & 0 & 0 & 1\end{array}$

0

Enzyme activity

\begin{tabular}{lllllllllllllllllll}
2 & 2 & 1 & 0 & 3 & 2 & 2 & 3 & 0 & 1 & 1 & 0 & 1 & 0 & 0 & 5 & 0 & 0 & 0 \\
1 & 3 & 2 & 0 & 1 & 0 & 0 & 0 & 0 & 1 & 2 & 0 & 0 & 0 & 1 & 5 & 4 & 1 & 0 \\
1 & 2 & 0 & 0 & 0 & 0 & 0 & 0 & 0 & 1 & 2 & 0 & 0 & 0 & 1 & 4 & 4 & 1 & 0 \\
2 & 1 & 1 & 0 & 1 & 0 & 1 & 1 & 1 & 3 & 3 & 0 & 1 & 0 & 1 & 5 & 5 & 1 & 0 \\
1 & 2 & 1 & 0 & 0 & 0 & 0 & 0 & 0 & 1 & 1 & 0 & 0 & 0 & 0 & 4 & 4 & 0 & 0 \\
5 & 3 & 1 & 0 & 2 & 1 & 1 & 0 & 0 & 4 & 5 & 3 & 2 & 0 & 1 & 5 & 5 & 1 & 0 \\
4 & 1 & 1 & 0 & 0 & 1 & 0 & 0 & 0 & 2 & 2 & 1 & 0 & 0 & 0 & 5 & 5 & 1 & 0 \\
\hline
\end{tabular}


Table 3. Enzymatic activity of fungi isolated from fruits

\begin{tabular}{|c|c|c|c|c|c|c|c|c|c|c|c|c|}
\hline \multirow[b]{2}{*}{ Medium } & \multicolumn{6}{|c|}{ Total enzyme activity } & \multicolumn{6}{|c|}{ No. of active enzymes } \\
\hline & 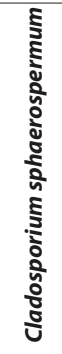 & 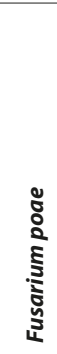 & 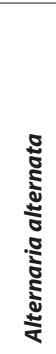 & 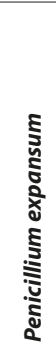 & 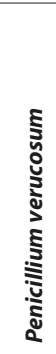 & 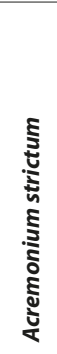 & 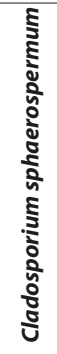 & 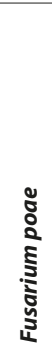 & 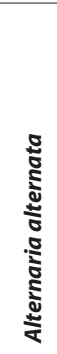 & 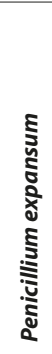 & 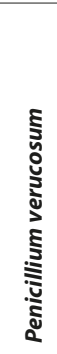 & 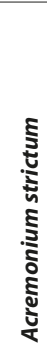 \\
\hline Czapek-Dox & $28^{*}$ & $18^{*}$ & $22 *$ & $27^{*}$ & $45^{*}$ & $14^{*}$ & 9 & 6 & 9 & 12 & 13 & 7 \\
\hline Czapek-Dox + raspberry & 20 & 23 & $31^{*}$ & 24 & 32 & $23^{*}$ & 10 & 11 & 10 & 8 & 9 & 9 \\
\hline Czapek-Dox + strawberry & $20^{*}$ & $21^{*}$ & 44 & 22 & 31 & 29 & 10 & 10 & 18 & 7 & 9 & 9 \\
\hline Czapek-Dox + apple & 21 & 16 & 18 & $38^{*}$ & $38^{*}$ & 24 & 10 & 8 & 10 & 11 & 11 & 10 \\
\hline Sabouraud + raspberry & 28 & 14 & $13^{*}$ & 34 & 34 & $3^{*}$ & 14 & 7 & 8 & 10 & 10 & 3 \\
\hline Sabouraud + strawberry & $36^{*}$ & $39 *$ & 44 & 41 & 34 & 2 & 13 & 14 & 13 & 13 & 11 & 2 \\
\hline Sabouraud + apple & 35 & 23 & 14 & $41^{*}$ & $35^{*}$ & 11 & 13 & 10 & 9 & 12 & 12 & 5 \\
\hline
\end{tabular}

* Statistical data analysis: Wilcoxon test $(\mathrm{p}=0.09117)$ and Mann-Whitney test $(\mathrm{p}=0.4185)$

Strawberries stimulated the action of this enzyme at the highest level (40 nmoles or more of the hydrolyzed substrate). In contrast, $\mathrm{N}$-acetyl- $\beta$-glucosaminidase increased its activity on every medium with the addition of fruit. The presence of fruit can also partially or completely inhibit the activity of selected enzymes. $P$. verrucisum exhibited maximal activity of leucine arylamidase on Czapek-Dox medium. The addition of strawberries or apples reduced the activity of this enzyme, while the addition of raspberries caused complete inactivation of this hydrolase.

Total enzymaticactivity on media without added fruit showed differences for individual strains. For C. sphaerospermum, $F$. poae, and $P$. expansum, the total hydrolase activity was higher on the Czapek-Dox medium. However, for the A. alternata, $P$. verrucosum and $A$. structum strains, the total hydrolase activity was greater on the Sabouraud medium.

The obtained results of enzymatic activity of fungi cultivated without and with the addition of fruit, which were the place of isolation of individual species, did not show statistically significant differences.

\section{DISCUSSION}

Fungal pathogens are a serious problem for both food safety and human health, for example, phytopathogenic fungi belonging to the genus Penicillium, Fusarium, Alternaria, Acremonium [16], as well as Cladosporium [17], may produce harmful allergens and/or mycotoxins. These fungi show numerous differences in the production of hydrolytic enzymes when interacting with fruit, such as raspberries, strawberries or apples. Identification and expression of the produced hydrolytic enzymes are crucial for determining the pathogenesis of fungi.

In the presented study, fungi of the genus Penicillium showed the highest total enzymatic activity. Among the investigated fruit, the highest enzymatic activity was recorded in the presence of apples. Gong et al. [18] reported that $P$. expansum is one of the most important pathogens of apples, causing, among others, blue rot of apples. Qin et al. [19] conducted studies which confirmed that hydrolytic enzymes may be an important virulence factor in P. expansum. They identified proteins the expression of which is manifested by increased levels of carbonyl proteins and an increased level of the reactive oxygen species. $P$. verrucosum is an equally important pathogen from the Penicillium genus isolated from apples, according to a study by Spotts et al. [20]. In addition, these fungi are the cause of allergic reactions in humans due to the large number of spores that can easily enter the respiratory system and also produce mycotoxins [21].

Fusarium poae is another species of fungi that pose a threat to human health. In the case of supplementation of medium with strawberries, the enzymatic activity increased significantly, whereas in the case of apples it decreased. Obtained results may indicate increased pathogenic potential in the case of contact with strawberries compared to apples. Currently, there is little information on the mechanisms associated with hydrolytic enzymes as the virulence factors of these fungi in fruits. However, fungi of the genus Fusarium have the ability to secrete enzymes degrading compounds contained in the plant cell wall. Marin et al. [22] detected the presence of polysaccharide-degrading enzymes in maize grains, while Żukiewicz-Sobczak et al. [23] showed an increase in the enzymatic activity of some species of Fusarium spp. on medium with the addition of wheat. Fungi of the genus Fusarium, including F. poae, are often the cause of onychomycosis or keratitis in people with a properly functioning immune system, while immuno-suppression can lead to deep and disseminated infections [24]. Similar results were obtained in the case of Alternaria alternata, where supplementation of medium with strawberries, significantly increased the activity of hydrolytic enzymes, and supplementation with apples reduced the activity of these enzymes. Alternaria spp. species are characterized by a wide range of environmental conditions, which indicates the possibility of colonization of new habitats. Therefore, special attention should be paid to food products that form the basis of nutrition [25]. Fungi of the genus Alternaria are often the cause of infection of the upper respiratory tract and may lead to the development of asthma [26]. 
Supplementation of medium with the addition of fruit reduces the general activity of $C$. sphaerospermum, which can have a positive effect on both plants and humans. Although they are the cause of many human allergies, so far not much attention has been paid to these fungi. Yew et al. [27] conducted research identifying a number of hydrolytic enzymes in C. sphaerospermum. Among them, numerous carbohydrate enzymes have been detected, the activity of which causes degradation of the cell wall of plants in order to obtain a source of carbon necessary for the development of infection in plants. Studies have also shown the presence of peptidases which, when inhaled into the lungs along with spores, can cause lung tissue disruption.

The lowest enzymatic activity was noted for A. strictum. Of the fungi examined, A. strictum has the lowest pathogenic potential in terms of the action of hydrolytic enzymes. Supplementation of medium with fruit, however, increases the enzymatic activity of these fungi, with may also increase their pathogenic potential. Racedo et al. [28] described A. strictum as one of the causative factors causing strawberry diseases. In humans, $A$. strictum is the cause of many skin and subcutaneous infections [29].

Studies by Manisha etal. [30] show that most phytopathogenic fungi cause serious diseases in humans. Of 17 species of fungal phytopathogens isolated from the soil in gardens, only two were not pathogenic for humans. Inhaling soil particles, as well as contact with spoiled fruit, is particularly dangerous for gardening workers. Infections with phytopathogenic fungi in humans are often asymptomatic but may give way to allergies. In the case of frequent contact with fungi, subclinical allergies may develop into serious respiratory allergies.

\section{CONCLUSION}

The activity of hydrolytic enzymes in isolated fungi depends on the addition of fruit and the type of the medium. Individual fruits can increase or decrease the enzymes activity. Fungi present in fruits may cause human diseases or infectious of allergic or toxic origin. The production of enzymes may increase the risk, especially in the case of allergic disorders.

\section{REFERENCES}

1. De Lucca AJ. Harmful fungi in both agriculture and medicine. Rev Iberoam Micol. 2007; 24: 3-13.

2. Almeida F, Rodrigues ML, Coelho C. The still underestimated problem of fungal diseases worldwide. Front Microbiol. 2019; 10: 214. https:// doi.org/10.3389/fmicb.2019.00214

3. Khare E, Yadav A. The role of microbial enzyme systems in plant growth promotion. Clim Chang Environ Sustain. 2017; 5(2): 122-145. https:// doi.org/10.5958/2320-642X.2017.00013.8

4. Kłapeć T, Cholewa G, Cholewa A, et al. Fungal diversity of root vegetables and soil rhizosphere collected from organic and conventional farms in Eastern Poland. Ann Agr Env Med. 2018; 25(2): 374-381. https://doi.org/10.26444/aaem/92143

5. Köhler JR, Casadevall A, Perfect J. The spectrum of fungi that infects humans. Cold Spring Harb Perspect Med. 2015; 5(1): a019273. https:// doi.org/10.1101/cshperspect.a019273

6. Mezzetti B, Giampieri F, Zhang Y, et al. Status of strawberry breeding programs and cultivation systems in Europe and the rest of the world. J Berry Res. 2018; 8: 205-221. https://doi.org/10.3233/JBR-180314

7. Prusky DB, Wilson RA. Does increased nutritional carbon availability in fruit and foliar hosts contribute to modulation of pathogen colonization? Postharvest Biol Technol. 2018; 145: 27-32. https://doi. org/10.1016/j.postharvbio.2018.05.001
8. Molnárová J, Vadkertiová R, Stratilová E. Extracellular enzymatic activities and physiological profile of yeasts colonizing fruit trees. J Basic Microb. 2014; 54(1): S74-84. https://doi.org/10.1002/jobm.201300072

9. Karkowska-Kuleta J, Rapala-Kozik M, Kozik A. Fungi pathogenic to humans: molecular bases of virulence of Candida albicans, Cryptococcus neoformans and Aspergillus fumigatus. Acta Biochim Pol. 2009; 56(2): 211-224. https://doi.org/10.18388/abp.2009_2452

10. Mustafa U, Kaur G. Extracellular enzyme production in Metarhizium anisopliae isolates. Folia Microbiol. 2009; 54(6): 499-504. https://doi. org/10.1007/s12223-009-0071-0

11. de Vries RP, Visser J. Aspergillus enzymes involved in degradation of plant cell wall polysaccharides. Microbiol Mol Biol Rev. 2001; 65(4): 497-522. https://doi.org/10.1128/MMBR.65.4.497-522.2001

12. Lamichhane JR, Venturi V. Synergisms between microbial pathogens in plant disease complexes: a growing trend. Front Plant Sci. 2015; 6: 385. https://doi.org/10.3389/fpls.2015.00385

13. Ebanks JP, Koshoffer A, Wickett RR, et al. Hydrolytic enzymes of the interfollicular epidermis differ in expression and correlate with the phenotypic difference observed between light and dark skin. J Dermatol. 2013; 40(1): 27-33. https://doi.org/10.1111/j.1346-8138.2012.01634.x

14. Schaller M, Borelli C, Korting HC, et al. Hydrolytic enzymes as virulence factors of Candida albicans. Mycoses. 2005; 48(6): 365-377. https://doi.org/10.1111/j.1439-0507.2005.01165.x

15. Bang WS, Chung HJ. Effect of high hydrostatic pressure on the enzyme activities in Saccharomyces cerevisiae and Escherichia coli. N Biotech. 2010; 27: 440-444. https://doi.org/10.1016/j.nbt.2010.03.001

16. Paterson RRM, Lima N. Filamentous fungal human pathogens from food emphasising Aspergillus, Fusarium and Mucor. Microorganisms. 2017; 5(3): 44. https://doi.org/10.3390/microorganisms5030044

17. Baxi SN, Portnoy JM, Larenas-Linnemann D, et al. Exposure and health effects of fungi on humans. J Allergy Clin Immunol Pract. 2016; 4(3): 396-404. https://doi.org/10.1016/j.jaip.2016.01.008

18. Gong D, Bi Z, Li Z, et al. Both Penicillium expansum and Trichothecium roseum infections promote the ripening of apples and release specific volatile compounds. Front Plant Sci. 2019; 10: 338. https://doi. org/10.3389/fpls.2019.00338

19. Qin G, Tian S, Chan Z, et al. Crucial role of antioxidant proteins and hydrolytic enzymes in pathogenicity of Penicillium expansum. Mol Cell Proteomics. 2007; 6(3): 425-438. https://doi.org/10.1074/mcp. M600179-MCP200

20. Spotts RA, Holmes RJ, Washington WS. Sources of spores and inoculum concentrations related to postharvest decay of apple and pear. Austr Plant Path. 1988; 17(2): 48-52. https://doi.org/10.1071/APP9880048

21. Moss MO. Fungi, quality and safety issues in fresh fruits and vegetables. J Appl Microbiol. 2008; 104(5): 1239-1243. https://doi.org/10.1111/ j.1365-2672.2007.03705.x

22. Marín S, Sanchis V, Ramos AJ, et al. Effect of water activity on hydrolytic enzyme production by Fusarium moniliforme and Fusarium proliferatum during colonisation of maize. Int J Food Microbiol. 1998; 42(3): 185-194. https://doi.org/10.1016/S0168-1605(98)00077-4

23. Żukiewicz-Sobczak WA, Cholewa G, Sobczak P, et al. Enzymatic activity of fungi isolated from crops. Post Dermatol Alergol. 2016; 33(6): 457-463. https://doi.org/10.5114/ada.2016.63885

24. van Diepeningen AD, Brankovics B, Iltes J, et al. Diagnosis of Fusarium infections: approaches to identification by the clinical mycology laboratory. Diagn Curr Fungal Infect Rep. 2015; 9: 135-143. https:// doi.org/10.1007/s12281-015-0225-2

25. Somma S, Amatulli MT, Masiello M, et al. Alternaria species associated to wheat black point identified through a multilocus sequence approach. Int J Food Microbiol. 2019; 293: 34-43. https://doi.org/10.1016/j. ijfoodmicro.2019.01.001

26. Leino MS, Loxham M, Blume C, et al. Barrier disrupting effects of Alternaria alternata extract on bronchial epithelium from asthmatic donors. PLoS One. 2013; 8(8): e71278. https://doi.org/10.1371/journal.pone.0071278

27. Yew SM, Chan ChL, Ngeow YF, et al. Insight into different environmental niches adaptation and allergenicity from the Cladosporium sphaerospermum genome, a common human allergy-eliciting Dothideomycetes. Sci Rep. 2016; 6: 27008. https://doi.org/10.1038/srep27008

28. Racedo J, Salazar SM, Castagnaro AP, et al. A strawberry disease caused by Acremonium strictum. Eur J Plant Pathol. 2013; 137: 649-654. https:// doi.org/10.1007/s10658-013-0279-3

29. Hilmioglu MDJ, Tasbakan M, Pullukcu H, et al. Skin infection on both legs caused by Acremonium strictum (case report). Ann Saudi Med. 2015; 35(5): 406-408. https://doi.org/10.5144/0256-4947.2015.406

30. Manisha K, Pawar N. Morpho-pathological effects of isolated fungal species on human population. Sci Reports. 2012; 1(1): 521-526. https:// doi.org/10.4172/scientificreports.521 